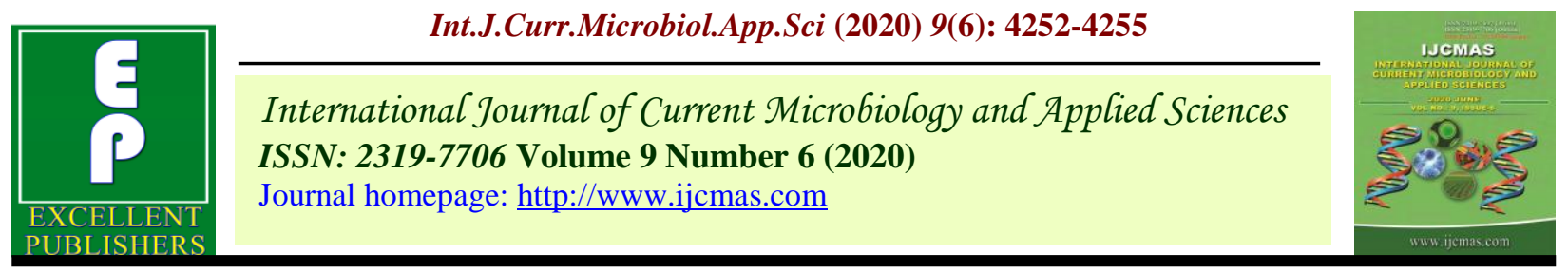

Case Study

https://doi.org/10.20546/ijcmas.2020.906.499

\title{
Pathology of Rabies in Pup Mortality
}

\author{
K. Arulanandam*, R. Sridhar, M. Thangapandiyan and C. Balachandran \\ Department of Veterinary Pathology, Madras Veterinary College, Chennai - 600007, India \\ *Corresponding author
}

\section{A B S T R A C T}

\begin{tabular}{|l|}
\hline Ke y w o r d s \\
Pup, Rabies, \\
$\begin{array}{l}\text { WMVG stain, } \\
\text { Negri bodies }\end{array}$ \\
\hline Article Info \\
\hline $\begin{array}{l}\text { Accepted: } \\
\text { 12 May } 2020 \\
\text { Available Online: } \\
\text { 10 June } 2020\end{array}$ \\
\hline
\end{tabular}

A study was carried out to know the incidence of rabies in pup mortality below 6 months of age at the department of Veterinary Pathology. Eleven pups were recorded as rabies during the one year period. Six were not vaccinated, vaccination history was not known in four pups and post bite vaccination was done in one pup. All except one (Labrador retriever) were partially owned nondescript pups. One to nine days duration of illness, hypersalivation, hyperaesthesia, aggressive behaviour, staggering gait and not responding to owner's call, dropped jaw, copper coloured tongue and biting inanimate objects were found. Two showed pulpy brain. In WMVG staining, nine impressions revealed Negri bodies. On histopathology, brain revealed degeneration and perivascular cuffing in six pups. Intracytoplasmic inclusions were observed in four brains.

\section{Introduction}

Rabies is a fatal neurological disease of warm blooded animals globally. The disease is endemic in about 100 countries. Stray dogs were the main source of infection in animals and humans (Nandi and Kumar, 2010). White et al. (2007) observed rabies in a 10 weeks old pup and emphasized the importance of early consideration of rabies as an important differential diagnosis in all puppies with behavioral or neurologic abnormalities. Eng and Fishbein (1990) reported that the important clinical signs in rabid dogs were paralysis (29 per cent) whereas Silva et al.
(2004) observed aggressive behaviour (77 per cent), lack of coordination and paralysis (42 per cent). In a study of rabid dogs, 72.72 per cent (8/11) showed hypersalivation, 54.54 (6/11) biting behaviour/aggressiveness and pica (Mugale et al., 2013).

Sumedha (2010) reported that there were no specific gross lesions in rabid dogs. Negri bodies appeared as a single or multiple, eosinophilic intracytoplasmic inclusions within the Purkinje neurons, axon and in the neurons of hippocampus (Rissi et al., 2008; Sumedha, 2010 and Mugale et al., 2013). Histopathologic evidence of rabies 
encephalomyelitis in brain and meninges were mononuclear infiltration, perivascular cuffing of lymphocytes or polymorphonuclear cells, lymphocytic foci, Babes nodules consisting of glial cells and Negri bodies (CDC, 2011). Mugale et al. (2013) reported that the main histopathological changes in rabid dogs were satellitosis (8/11), Negri bodies (7/11), gliosis, neuronophagia and congestion in the brain (6/11). Praveena et al. (2007) reported that the rabies virus was usually demonstrated in brain tissue by impression smear and further stated that histopathological examination of brain tissue and cytological examination of impression smear for Negri bodies.

\section{Materials and Methods}

A total number of 11 suspected pups less than 6 months of age were admitted in rabies unit and after death impression smear from brain were collected for staining. Brain was collected in $10 \%$ formalin for histopathology.

\section{William's Modified van Gieson's stain (WMVG)}

Stock solution: Saturated alcoholic solutions of basic fuchsin and methylene blue. Working

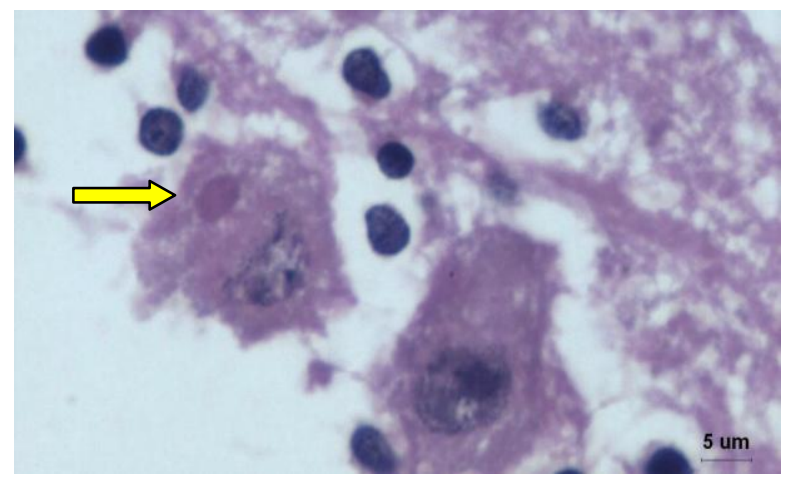

Brain - Intracytoplasmic inclusion $\mathrm{H} \& \mathrm{E}$ solution was freshly prepared by mixing 3 drops of basic fuchsin, 7 drops of methylene blue in $10 \mathrm{~mL}$ of distilled water.

\section{Results and Discussion}

11 pups were recorded as rabies below the age groups of 6 months. Out of 11 cases, 6 were not vaccinated and vaccination history was not known in 4 cases. Post bite vaccination was done in one case. All except one (Labrador retriever) were non-descript pups. The duration of illness varied from one to nine days. The important clinical signs observed were hypersalivation, hyperaesthesia, aggressive behaviour, staggering gait and not responding to owner's call, dropped jaw, copper coloured tongue and biting inanimate objects. Out of 11 cases, brains from two cases were pulpy. Hence, in WMVG staining out of the 11 cases, only nine impressions revealed Negri bodies and in two cases it was inconclusive because of autolysis. No gross abnormalities were identified during post-mortem examination. Histopathological examination of brain revealed oedema, mild, multifocal areas of congestion, gliosis, spongiosis, chromatolysis and neuronal degeneration in all the cases.

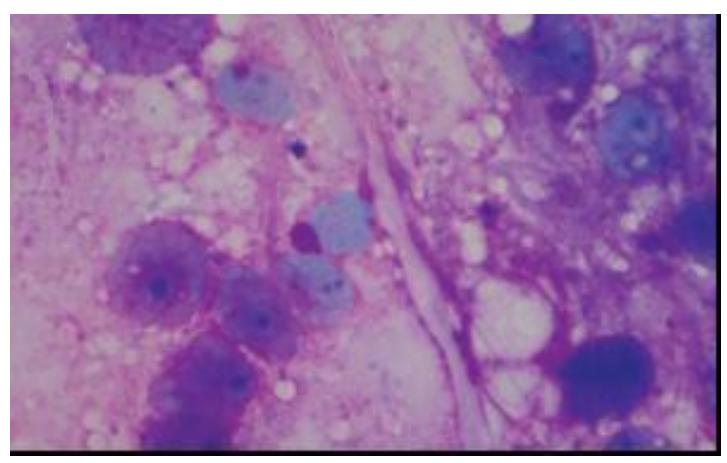

Hippocampus impression - Negri bodies in WMVG 
Neuronophagia, haemorrhage, satellitosis, perivascular cuffing were observed in six cases. Mild to moderate lymphocytic infiltration and intracytoplasmic inclusions were observed in four cases. Decrease in Purkinje cell population, meningeal vessels congestion with MNC infiltration was observed in two cases.

During the period of study, 11 rabies cases were recorded in pups below the age group of 6 months. Out of 11 cases, 6 were not vaccinated and vaccination history was not known in 4 cases. Post bite vaccination was done in one case. All except one (Labrador retriever) were non-descript pups which were partially owned. This was in agreement with Nandi and Kumar (2010) who reported that stray dogs were the main source of infection in animals. In our study, rabies was observed at the lowest age of 35 days. Whereas, White et al. (2007) observed rabies in a 10 weeks old pup and emphasized the importance of early consideration of rabies in puppies. One to nine days duration of illness, hypersalivation, hyperaesthesia, aggressive behaviour, staggering gait and not responding to owner's call, dropped jaw, copper coloured tongue and biting inanimate objects agreed with reports of earlier workers (Eng and Fishbein, 1990, Silva et al., 2004; Mugale et al., 2013). Out of 11 cases, two of them showed pulpy brain. Hence, WMVG staining only nine impressions revealed Negri bodies. No gross abnormality was detected as per Sumedha (2010). Brain revealed gliosis, spongiosis, neuronal degeneration, neuronophagia, satellitosis, perivascular cuffing in six cases. These changes were in agreement with CDC (2011) and Mugale et al. (2013). In our study, intracytoplasmic inclusions were observed only in 4/9 cases. Similarly Mugale et al. (2013) observed inclusions only in 7/11 cases examined.

The present paper concludes the prevalence of rabies in pups and also the various clinical signs and histopathological changes in brain due to the rabies virus. The presence of negri bodies in the impression smear made from hippocampus and the brain tissue is the confirmative diagnosis. William's Modified van Gieson's stain is the easy, quick reliable stain for the diagnosis of negri bodies in the impression smear of brain.

\section{References}

CDC.2011. www.cdc.gov/rabies/ 27 April 2013.

Eng TR and Fishbein DB. 1990. Epidemiologic factors, clinical findings and vaccination status of rabies in cats and dogs in the united states in 1988. Journal of American Veterinary medical Association, 197: 201

Mugale MN, Sandhu BS, Gupta K, Sood NK, Beigh A, Singh CK. 2013. Comparison of various techniques used for diagnosis of rabies in cats. Eurasian Journal of Veterinary Sciences, 29 (2), 92-96

Nandi S, Kumar M. 2010. Development in immunoprophylaxis against rabies for animals and humans. Avicenna Journal of Medicine Biotechnology, 2: 3-21

Praveena E, Jayakumar PR, Balachandran C, Thirumurugan G, Dhinakar Raj G, Murali Manohar B. 2007. Detection of rabies virus genes by In-Situ polymerase chain reaction. Veterinary Research Communications, 31: 775-781

White J, Taylor SM, Wolfram KL and O'Conner BP. 2007. Rabies in a 10week-old puppy. Canadian Veterinary Journal, 48: 931-934

Rissi DR, Felipe P, Glausia DK and Barros SL. 2008. Occurrence of rabies in sheep in Rio Grande do Sul, Brazil. Pesquisa Veterinaria Brasileria, 28:10

Silva LHQ, Bissoto CE, Delbem ACB, Ferrari CIDL, Perri SHV, Nunes CM, Ferrari CI Da-Silva LHQ. 2004. Canine rabies epidemiology in Aracatuba and neighbourhood, Northwestern Sao Poula state-Brazil. Revista da Sociedade 
Brasileira de Medicina Tropical, 37: 13942.

Sumedha. 2010. Antemortem and postmortem detection of rabies virus antigen in natural cases of rabies in animals- an

immunopathological study (M.V.Sc., Dissertation). Guru Angad Dev Veterinary and Animal Sciences University, Ludhiana, India.

\section{How to cite this article:}

Arulanandam, K., R. Sridhar, M. Thangapandiyan and Balachandran, C. 2020. Pathology of Rabies in Pup Mortality. Int.J.Curr.Microbiol.App.Sci. 9(06): 4252-4255.

doi: https://doi.org/10.20546/ijcmas.2020.906.499 